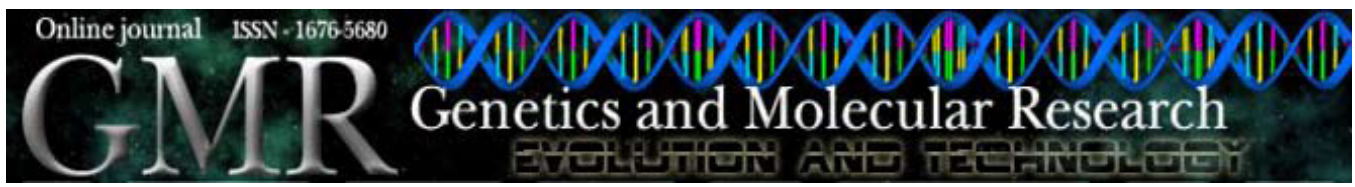

$\underline{\text { Case Report }}$

\title{
Benefits of kinesiotherapy and aquatic rehabilitation on sickle cell anemia. A case report
}

\author{
G. Tinti ${ }^{1}$, R. Somera Jr. ${ }^{1}$, F.M. Valente ${ }^{2}$ and C.R.B. Domingos ${ }^{3}$ \\ ${ }^{1}$ Departamento de Fisioterapia, Universidade Paulista, \\ São José do Rio Preto, SP, Brasil \\ ${ }^{2}$ Departamento de Fisioterapia, \\ Universidade Federal Paulista, São Paulo, SP, Brasil \\ ${ }^{3}$ Departamento de Biologia, \\ Universidade Estadual Paulista "Julio de Mesquita Filho", \\ São José do Rio Preto, SP, Brasil \\ Corresponding author: F.M. Valente \\ E-mail: flaviamvalente@hotmail.com
}

Genet. Mol. Res. 9 (1): 360-364 (2010)

Received November 14, 2009

Accepted December 14, 2009

Published March 2, 2010

\begin{abstract}
The process of hemoglobin polymerization and the consequent sickling of red blood cells that occurs in patients with sickle cell disease shortens the half-life of red blood cells. It causes vaso-occlusive complications, as well as pain and pulmonary and cardiovascular dysfunction. We evaluated an aquatic rehabilitation program used for patients with sickle cell anemia and examined the possible benefits that exercise in warm water has for the circulatory system, for relieving pain, and for increasing lung capacity. The patient was a 32-year-old female. The parameters that we used in this study include respiratory muscle strength (which was calculated by measuring maximum inspiratory pressures and maximum expiratory pressures), the McGill and Wisconsin pain questionnaires (in order to evaluate the patients' characterizations and descriptions of their pain), and the SF-36 Health Survey. The treatment included warm water exercises, stretching, aerobic exercise, and relaxation, during two sessions of 45 min per week for 5 weeks. The patient experienced a significant decrease in pain, a significant increase in
\end{abstract}


the strength of respiratory muscles, and improved quality of life. We conclude that aquatic rehabilitation can be used to improve the clinical condition of sickle cell anemia patients, and we encourage more research on this new treatment regime, in comparison with other types of therapies.

Key words: Sickle cell anemia; Hemoglobinopathy; Kinesiotherapy; Aquatic rehabilitation

\section{INTRODUCTION}

Sickle cell anemia is a serious genetic condition caused by the substitution of a glutamic acid for avaline at position six of the beta globin chain ( $\beta 6 \mathrm{Glu}-\mathrm{Val})$. It leads to polymer formation when patients experience low oxygen levels, which results in sickling of the red blood cells, causing health complications (Naoum and Naoum, 2004). These complications include severe musculoskeletal and cardiovascular pain, which clinically manifests as palpitations, dyspnea, and fatigue; these symptoms worsen during physical exercise. The primary factors responsible for cardiovascular manifestations are vaso-occlusive events, which prevent the transport of oxygen to the tissues (Ingram, 1989; Martins et al., 1998).

Kinesiotherapy (and, more specifically, aquatic rehabilitation) is a treatment technique that causes a physiological response, including relaxed arterial and venous muscle tone, lower blood pressure, a higher cardiac frequency and volume of ejection, an increased supply of blood to the muscles, higher muscle metabolism, and more circulation in the limbs (Campion, 2000). All these changes, such as the redistribution of blood resulting from immersion (hydrostatic pressure), lead to vasodilatation, venous return (Becker and Cole, 2000), and freer movement of tissue fluids, which aids in the removal of metabolites, improves tissue nutrition and helps the healing process (Campion, 2000).

A preventative physiotherapeutic approach for the treatment of complications resulting from sickle cell anemia is rarely reported in the literature (Ingram, 1989; Martins et al., 1998), but the literature does encourage the use of physiotherapy as part of an interdisciplinary treatment program that offers the adequate attention needed by these patients (Naoum and Naoum, 2004). We examined the effects of kinesiotherapy and aquatic rehabilitation on pain levels and lung capacity in an adult woman with sickle cell anemia.

\section{MATERIAL AND METHODS}

A female patient, 32 years old, had been diagnosed to have sickle cell anemia at 8 years old; she was homozygous for the Bantu haplotype. Between 16 and 18 years old, the patient was repeatedly hospitalized for infections, leg ulcers, generalized pain, and anemia. The patient reported being forced to leave her job approximately four years before, when pain was the most frequent and intense. Because the patient was an adult, hydroxyurea was offered as treatment, but the patient opted not to take this medication due to its adverse side effects. The primary complaints reported during her clinical evaluation were apathy, depression, frequent fatigue, and constant, generalized pain. The patient reported that she had not been engaging in any physical activity after suffering from tachypnea and tachycardia during light exertion. In order to improve the patient's lung capacity and to relieve her pain, physiotherapy was pro- 
posed (including a complete physiotherapeutic evaluation).

During her evaluation, the patient responded to the SF-36 Health Survey (Ware Jr. and Sherbourne, 1992; Ciconelli et al., 1999), the McGill pain questionnaire (translated into Portuguese; Pimenta and Teixeira, 1997), and the Wisconsin pain survey (Graham et al., 1980). An evaluation was made of her respiratory muscle strength by measuring maximum inspiratory pressure and maximum expiratory pressure, with a spirometer $\left(\right.$ GERAR $\left.^{\circledR}\right)$. Physiotherapy was recommended in order to improve the patient's lung capacity and was initiated after the patient's clinical evaluations and excluding other possible cardiac problems that would have explained the patient's condition.

\section{RESULTS AND DISCUSSION}

A kinesiotherapy/aquatic rehabilitation plan was developed; it consisted of exercise in warm water, stretching, aerobics, and relaxation. The sessions were performed in a swimming pool heated to a temperature of $34^{\circ} \mathrm{C}$ for $45 \mathrm{~min}$, twice a week, for 10 sessions; the evaluation methods described above were applied before the first session and after the 10th session.

Changes in the composition of hemoglobin lead to complications characteristic of sickle cell disease. These changes have significant negative effects on the quality of life of the patients, which we also observed in the responses to the questionnaires (Tables 1-3).

The pain experienced by the patient was reduced after the first therapy session (Table 2). The patient's quality of life also improved (Table 1). This proves the benefits of physical activity in water, particularly the patient's newfound ability to move in ways that she was initially unable to.

Among the pain index parameters from the McGill questionnaire, we also calculated the percentages in the reduction of pain symptoms using the descriptors evaluative and miscellaneous, which improved approximately $40 \%$ (Table 2 ). In the responses to the Wisconsin questionnaire, relief from pain and relations with other people improved most (Table 3). Only mood did not change from pre- to post-treatment.

\begin{tabular}{lcc} 
Table 1. Pre- and post-treatment values from the SF-36 Health Survey. \\
\hline Descriptors & Pre-treatment & Post-treatment \\
\hline Mental health & 40 & 60 \\
Emotional role & 0 & 33 \\
Social role & 25 & 88 \\
Vitality & 25 & 50 \\
General health & 5 & 42 \\
Pain & 50 & 93 \\
Physical role & 0 & 75 \\
Physical functioning & 45 & 50 \\
\hline
\end{tabular}

A value of zero (0) corresponds to the most negative result (lowest quality of life), while a value of 100 corresponds to the most positive result (highest quality of life).

\begin{tabular}{|c|c|c|}
\hline Descriptors & Pre-treatment pain index & Post-treatment pain index \\
\hline Sensory & 33 & 30 \\
\hline Affective & 11 & 9 \\
\hline Evaluative & 5 & 3 \\
\hline Miscellaneous & 7 & 4 \\
\hline
\end{tabular}




Table 3. Results from the Wisconsin Pain Questionnaire, with zero $(0)$ as the most positive score (the least pain)
\begin{tabular}{lcc} 
and 10 as the most negative (the most pain). & Pre-treatment & Post-treatment \\
\hline Descriptors & 8 & 7 \\
\hline Enjoyment of life & 5 & 4 \\
Sleep & 8 & 5 \\
Relations with other people & 7 & 5 \\
Work & 8 & 7 \\
Walking ability & 6 & 6 \\
Mood & 7 & 4 \\
General activity & 10 & 7 \\
Pain on the average & 4 & 1 \\
Pain at its least & 10 & 8 \\
Pain at its worst & & \\
\hline
\end{tabular}

The maximum inspiratory pressure was 76.7 and $79.2 \mathrm{cmH}_{2} \mathrm{O}$, before and after treatment, respectively. The maximum expiratory pressure was 81.3 and $85.4 \mathrm{cmH}_{2} \mathrm{O}$, before and after treatment, respectively. This level of improvement was important to the patient, who reported that she could walk for longer distances without experiencing fatigue.

Intense physical exercise produces physiological changes that induce the formation of hemoglobin polymers in sickle cell anemia patients, due to the presence of Hemoglobin S. This process, which is caused by physical exertion, occurs as a result of dehydration, increased body temperature, hypoxia, and acidosis, which are also evident at times of stress. Once this process occurs, the chances of complications increase for sickle cell anemia patients (Klug et al., 1974; Ingram, 1989). In light of this, the kinesiotherapeutic exercises that were proposed for this patient were based on exercise physiology (Campion, 2000; Becker and Cole, 2000), with low intensity and velocity and intermittent breaks. The patient reported a decrease in fatigue (with a reduction in the frequency of the symptom) in both overt physical exertion and day-to-day activities.

Improvement in the social relation responses were also observed (Table 1). The patient reported more availability for events and activities. Initially, the patient had reported feelings of embarrassment and fear of not being taken seriously when she complained of her pain and limited movement, because there was no visible evidence for the cause of her limited movement and because she had previously experienced scolding and disregard when she sought help for her suffering.

\section{CONCLUSION}

Based on the results with this sickle cell anemia patient, we suggest that kinesiotherapy (more specifically, aquatic rehabilitation), at low intensity and in heated pools, can improve respiratory muscle strength and quality of life, and it can decrease pain.

\section{ACKNOWLEDGMENTS}

We thank the Brazilian foundation Conselho Nacional de Desenvolvimento Científico e Tecnológico (CNPq) for financial support.

\section{REFERENCES}

Becker BE and Cole AJ (2000). Terapia Aquática Moderna. Manole, São Paulo. 
Campion MR (2000). Hidroterapia: Princípios e Prática. Manole, São Paulo.

Ciconelli RM, Ferraz MB, Santos W, Meinão I, et al. (1999). Brazilian-Portuguese version of the SF-36. A reliable and valid quality of life outcome measure. [Tradução para a língua portuguesa e validação do questionário genérico de avaliação de qualidade de vida SF-36 (Brasil SF-36)]. Rev. Bras. Reumatol. 39: 143-150.

Graham C, Bond SS, Gerkovich MM and Cook MR (1980). Use of the McGill pain questionnaire in the assessment of cancer pain: replicability and consistency. Pain 8: 377-387.

Klug PP, Lessin LS and Radice P (1974). Rheological aspects of sickle cell disease. Arch. Intern. Med. 133: 577-590.

Martins WA, Mesquita ET, Cunha DM, Ferrari AH, et al. (1998). Alterações cardiovasculares na anemia falciforme. Arq. Bras. Cardiol. 70: 365-370.

Naoum PC and Naoum FA (2004). Doença das Células Falciformes. Sarvier, São Paulo.

Pimenta CAM and Teixeira MJ (1997). Avaliação da dor. Rev. Med. 76: 27-35.

Ingram VM (1989). A case of sickle-cell anaemia: a commentary on "Abnormal Human Haemoglobins. I. The Comparison of Normal Human and Sickle-Cell Haemoglobins by "Fingerprinting" with II. The Chymotryptic Digestion of the Trypsin-Resistant 'Core' of Haemoglobins A and S and III. The Chemical Difference Between Normal and Sickle Cell Haemoglobins. Biochim. Biophys. Acta 1000: 147-150.

Ware JE Jr and Sherbourne CD (1992). The MOS 36-item short-form health survey (SF-36). I. Conceptual framework and item selection. Med. Care 30: 473-483. 